\title{
Validation of the Liverpool Elbow Score for evaluation of elbow stiffness
}

\author{
Ziyang Sun ${ }^{1}$ and Cunyi Fan ${ }^{1,2^{*}}$
}

\begin{abstract}
Background: The Liverpool Elbow Score (LES) has been widely used to assess the outcomes of total elbow replacement in various conditions. However, there have been no published validation studies on LES for patients with stiff elbows undergoing arthrolysis. The purpose of this study was to find out whether LES could be equally applied to evaluate joint function in patients with elbow stiffness.

Methods: A total of 63 patients with elbow stiffness were included in this retrospective validation study. The LES combines a nine-item patient-answered questionnaire (PAQ) and a six-item clinical assessment score (CAS) , and can also be divided to evaluate two different parameters: elbow motion capacity (EMC) and elbow-related symptoms (ERS). Construct validity was assessed by correlating LES with previously validated scoring systems, and Spearman correlation coefficients (SCCS) were calculated. Effect size (ES) and standardized response mean (SRM) were calculated to determine responsiveness.

Results: There were no ceiling or floor effects in the target population. Good-to-excellent validity was determined based on total score (0.45-0.89), PAQ (0.42-0.88), CAS (0.35-0.60), EMC (0.46-0.86), and ERS (0.36-0.59). High responsiveness (ES/SRM) was observed in total score (2.80/2.24), PAQ (2.34/1.78), CAS (2.90/2.34), EMC (2.92/2.35), and ERS (0.55/0.52).

Conclusion: Our results suggest that the LES is a valid elbow-specific scoring system that can be used to evaluate joint function in patients with elbow stiffness, though some items included had some weakness either.
\end{abstract}

Keywords: Liverpool elbow score, Elbow stiffness, Scoring systems, Validation, Validity, Responsiveness

\section{Background}

Elbow stiffness is a well-recognized disabling condition that causes functional impairment in the upper limb and interferes with daily activities. It is a very common complication after injuries or secondary to arthropathy, as both bony and soft tissue factors are the most important aetiologies [1-3]. Patients with limited elbow motion usually complain of difficulties in work, leisure activities, and even basic activities of daily living. Sometimes they are troubled with symptoms like pain, numbness, weakness, and instability. Clinical scoring systems are the most popular functional measurements used in the evaluation of orthopaedic patients. These systems are

\footnotetext{
* Correspondence: cyfan@sjtu.edu.cn

${ }^{1}$ Department of Orthopaedics, Shanghai Jiao Tong University Affiliated Sixth People's Hospital, 600 Yishan Road, Shanghai 200233, People's Republic of China

2Department of Orthopaedics, Shanghai Sixth People's Hospital East Affiliated to Shanghai University of Medicine \& Health Sciences, Shanghai, People's
} Republic of China

(c) The Author(s). 2018 Open Access This article is distributed under the terms of the Creative Commons Attribution 4.0 International License (http://creativecommons.org/licenses/by/4.0/), which permits unrestricted use, distribution, and reproduction in any medium, provided you give appropriate credit to the original author(s) and the source, provide a link to the Creative Commons license, and indicate if changes were made. The Creative Commons Public Domain Dedication waiver (http://creativecommons.org/publicdomain/zero/1.0/) applies to the data made available in this article, unless otherwise stated. treatment effectiveness, and compare different treatment methods $[4,5]$.

The Liverpool Elbow Score (LES, Fig. 1) was first introduced in 2004 as an elbow-specific outcome score to be completed by both the clinicians and patients. The LES combines a nine-item patient-answered questionnaire (PAQ, P1-P9) and a six-item clinical assessment score (CAS, C1-C6) [6]. The CAS comprises items that evaluate range of motion (C1-C4), muscle strength (C5), and ulnar nerve function (C6), whereas the PAQ assesses function and the ability to perform activities of daily living (P1-P7), levels of pain (P8), and participation in sporting and recreational activities (P9). The components of the LES, similar to most other elbow-related scoring systems, could also be divided into 2 parts comprising elbow motion capacities (EMC, C1-C4 and P1-P7 and P9) and elbow-related symptoms (ERS, C5-C6 and P8). ERS covers the items pertaining to muscle strength (C5) and ulnar nerve function (C6) from 


\begin{tabular}{|c|c|c|c|c|c|}
\hline & Score 4 & Score 3 & Score 2 & Score 1 & Score 0 \\
\hline \multicolumn{6}{|l|}{ Clinical assessment } \\
\hline Cl Flexion & - & $>135^{\circ}$ & $120-135^{\circ}$ & $90-120^{\circ}$ & $<90^{\circ}$ \\
\hline C2 Extension & - & None & $<20$ & $20-30^{\circ}$ & $>30^{\circ}$ \\
\hline C3 Pronation (add 1 to score if wrist/forearm & athology) & - & $>50^{\circ}$ & $50-20^{\circ}$ & $<20^{\circ}$ \\
\hline \multicolumn{2}{|c|}{ C4 Supination (add 1 to score if wrist/forearm pathology) } & - & $>50^{\circ}$ & $50-20^{\circ}$ & $<20^{\circ}$ \\
\hline $\begin{array}{l}\text { C5 Strength: average of flexion, } \\
\text { extension, pronation and supination }\end{array}$ & $\begin{array}{l}\text { Apparently } \\
\text { normal }\end{array}$ & $\begin{array}{l}\text { Complete motion } \\
\text { against gravity and } \\
\text { some resistance }\end{array}$ & $\begin{array}{l}\text { Complete motion } \\
\text { against gravity }\end{array}$ & $\begin{array}{l}\text { Complete motion } \\
\text { with gravity } \\
\text { eliminated }\end{array}$ & Absent \\
\hline C6 Ulnar nerve & - & None & Sensory & $\begin{array}{l}\text { Motor: no } \\
\text { disability }\end{array}$ & $\begin{array}{l}\text { Motor: with } \\
\quad \text { disability }\end{array}$ \\
\hline \multicolumn{2}{|c|}{ Patient-answered questions: During the past four weeks: } & & & & \\
\hline $\begin{array}{l}\text { P1 How often have you had to use } \\
\text { your other arm to do things normally } \\
\text { done by the affected arm? }\end{array}$ & Never & Once or twice & Sometimes & Many times & Every time \\
\hline $\begin{array}{l}\text { P2 Has your elbow problem caused } \\
\text { you any difficulty in combing your hair? }\end{array}$ & None & Little & Moderate & Severe & Unable to do \\
\hline $\begin{array}{l}\text { P3 Has your elbow problem caused } \\
\text { you any difficulty in washing yourself? }\end{array}$ & None & Little & Moderate & Severe & Unable to do \\
\hline $\begin{array}{l}\text { P4 Has your elbow problem caused } \\
\text { you any difficulty in feeding yourself? }\end{array}$ & None & Little & Moderate & Severe & Unable to do \\
\hline $\begin{array}{l}\text { P5 Has your elbow problem caused } \\
\text { you any difficulty in dressing yourself? }\end{array}$ & None & Little & Moderate & Severe & Unable to do \\
\hline $\begin{array}{l}\text { P6 Has your elbow problem caused } \\
\text { you any difficulty in trying to do } \\
\text { household activities? }\end{array}$ & None & Little & Moderate & Severe & Unable to do \\
\hline $\begin{array}{l}\text { P7 Has your elbow problem caused you any } \\
\text { difficulty in lifting, e.g. a kettle, a milk } \\
\text { bottle, groceries? }\end{array}$ & None & Little & Moderate & Severe & Unable to do \\
\hline $\begin{array}{l}\text { P8 How would you describe the pain } \\
\text { from this elbow? }\end{array}$ & None & Little & Moderate & Severe & Unbearable \\
\hline $\begin{array}{l}\text { P9 Has your elbow problem affected your } \\
\text { sport and leisure activities? }\end{array}$ & None & Little & Moderate & Severe & Unable to do \\
\hline
\end{tabular}

the CAS and pain (P8) from the PAQ. The remaining items form the EMC (C1-C4, P1-P7 and P9). In the original study, all items were measured on a scale from 0 to 10 and transformed in the calculation of the final score. The final scores were calculated as "final scores $(\mathrm{LES})=(2 / 9) *(\mathrm{C} 1+$ $\mathrm{C} 2+\mathrm{C} 3+\mathrm{C} 4+\mathrm{C} 6)+(1 / 6) *(\mathrm{C} 5+\mathrm{P} 1+\mathrm{P} 2+\mathrm{P} 3+\mathrm{P} 4+$ $\mathrm{P} 5+\mathrm{P} 6+\mathrm{P} 7+\mathrm{P} 8+\mathrm{P} 9)$ ", with values ranging from 0 to 10. The lower scores represented greater symptom and functional severity. Detailed item distributions in each of the different parts along with the individual score calculations and score ranges are shown in Table 1.

After being demonstrated to be a reliable, valid and responsive outcome tool, the LES began to be used to assess outcomes after total elbow replacement in the management of rheumatoid arthritis [7, 8], posttraumatic arthritis [8-10], olecranon fractures [10] and distal humeral fractures $[11,12]$. However, there have been no published validation studies of LES for patients with stiff elbows undergoing arthrolysis. Additionally, a well-established validation study might not be applicable to different populations, which means that a previously validated tool might have to be re-validated to justify its use in different populations [13]. Therefore, the purpose of this study was to determine whether the LES can be equally applied in different populations to evaluate joint function in patients with elbow stiffness.

\section{Methods}

Translation procedure

All the scoring systems (LES: Liverpool Elbow Score; DASH: Disability of arm, shoulder and hand questionnaire; OES: Oxford Elbow Score; MEPS: Mayo Elbow Performance Score; SF-36: Short Form-36) used in this

Table 1 Items distribution, scores calculation and score ranges of LES and different parts

\begin{tabular}{|c|c|c|c|c|}
\hline \multirow[t]{2}{*}{ Part } & \multirow[t]{2}{*}{ Items distribution } & \multirow[t]{2}{*}{ Scores calculation } & \multicolumn{2}{|c|}{ Score ranges } \\
\hline & & & Best & Worst \\
\hline LES (total) & C1-C6, P1-P9 & $(2 / 9)^{*}(\mathrm{C} 1+\mathrm{C} 2+\mathrm{C} 3+\mathrm{C} 4+\mathrm{C} 6)+(1 / 6)^{*}(\mathrm{C} 5+\mathrm{P} 1+\mathrm{P} 2+\mathrm{P} 3+\mathrm{P} 4+\mathrm{P} 5+\mathrm{P} 6+\mathrm{P} 7+\mathrm{P} 8+\mathrm{P} 9)$ & 10 & 0 \\
\hline PAQ & P1-P9 & $(1 / 6)^{*}(P 1+P 2+P 3+P 4+P 5+P 6+P 7+P 8+P 9)$ & 6 & 0 \\
\hline CAS & $\mathrm{C} 1-\mathrm{C} 6$ & $(2 / 9)^{*}(C 1+C 2+C 3+C 4+C 6)+(1 / 6)^{*}(C 5)$ & 4 & 0 \\
\hline EMC & C1-C4, P1-P7, P9 & $(2 / 9)^{*}(\mathrm{C} 1+\mathrm{C} 2+\mathrm{C} 3+\mathrm{C} 4)+(1 / 6)^{*}(\mathrm{P} 1+\mathrm{P} 2+\mathrm{P} 3+\mathrm{P} 4+\mathrm{P} 5+\mathrm{P} 6+\mathrm{P} 7+\mathrm{P} 9)$ & 8 & 0 \\
\hline ERS & C5-C6, P8 & $(2 / 9)^{*}(\mathrm{C} 6)+(1 / 6)^{*}(\mathrm{C} 5+\mathrm{P} 8)$ & 2 & 0 \\
\hline
\end{tabular}


study were translated into Simplified Chinese (Mainland) versions prior to having patients complete the questionnaires. Among these, MEPS has been widely used in China to evaluate elbow function, and validations of DASH and SF-36 have been performed in China $[14,15]$. For LES and OES, however, there have been no other validation studies for these two scores in Simplified Chinese (Mainland) versions to this point.

Therefore, a 6-step method was used that included translation, synthesis, back-translation, expert committee review, pre-testing, and submission for appraisal, according to the guidelines of the cross-cultural adaptation process provided by Guillemin et al. [16, 17]. Briefly, the English versions of the LES and OES were translated separately by two native Chinese translators. A synthesized Simplified Chinese (Mainland) translation version was established after uniform agreement was reached between the two translators. The translated versions which was back-translated by two native English bilingual speakers who were blinded to the original English version. Then the four translators and two orthopaedic surgeons composed an expert committee that was established to compare the Chinese version to the original and back-translated versions. After an agreement on the semantic, idiomatic, experiential, and conceptual equivalence between the original and the target versions, and with an absence of language issues when the final version was pretested in 15 Chinese patients with elbow stiffness, the expert committee reached a consensus on the final version.

\section{Patients and study design}

This was a retrospective validation study of patients who presented to our institution for elbow arthrolysis secondary to elbow stiffness between September 2016 and December 2016. Exclusion criteria were (1) unwillingness to participate or cooperate with follow-up; (2) illiteracy or an inability to comprehend the contents of the questionnaires; and (3) mental illness. All the patients underwent open arthrolysis by the same surgeon (C. F.) [18]. During the study period, 81 patients underwent surgery for elbow stiffness at our institution. Of these, 68 met the inclusion criteria. However, 5 of the 68 were excluded because of refusal or loss to follow up. The remaining 63 included patients were 45 men and 18 women, with a mean age of 35 years and a mean followup time of 13 months (other demographics and characteristics are shown in Table 2). The sample size of the respondents for validation of a scoring system was assumed to exceed three times the number of items in the system [19]. Therefore, with a total of 15 items, a total sample size of 63 was considered sufficient. All patients were asked to complete the patient-rated parts of LES, DASH, OES and SF-36. The physician-rated parts of
Table 2 Demographics and clinical characteristics of patients

\begin{tabular}{ll}
\hline Characteristics & \\
\hline No. of patients & 63 \\
Male & $45(71)$ \\
Age, years & $35 \pm 13(11-62)$ \\
Height, cm & $169 \pm 9,(143-188)$ \\
Weight, Kg & $66 \pm 13,(32-105)$ \\
BMl, kg/m2 & $23.1 \pm 3.4(15.7-32.2)$ \\
Dominant arm & $34(54)$ \\
Follow-up time ${ }^{\text {, }}$, months & $13 \pm 1(12-15)$ \\
\hline
\end{tabular}

Categorical variables are presented as number (\%)

Continuous variables presented as mean \pm standard deviation, (range) $B M l$ body mass index

afollow-up time means month post-operation from elbow release

LES and MEPS were assessed following a written protocol so that all the patients were examined using the same method.

\section{Testing and evaluation of measurement qualities}

Floor and ceiling effects, reliability, construct validity, and responsiveness were required for a full validation of the scoring system $[20,21]$.

\section{Reliability}

Reliability measures whether the scores of the same patient show differences when implemented at different times or by different doctors (test-retest reliability), and whether the items in a domain have measured the same concept (internal consistency). However, this could not be measured due to the retrospective nature of our study.

\section{Construct validity}

Construct validity is defined as the degree to which the scores of a particular instrument are related to a gold standard test. Unfortunately, no gold standard test has been established to reflect pre- and post-arthrolysis status. The DASH can be used to measure disability in any region of the upper limb and has been shown to be valid and responsive compared to other joint-specific measures of the upper extremity, and comprises 2 parts (Disability and Symptoms) [22]. The OES was reported to be a valid, reliable, and responsive self-administered instrument that can be used for several types of elbow function measurements, and it comprise 3 parts (Pain, Elbow Function and Social-psychological) [23]. The DASH and OES have been shown to correlate to general health measures such as the SF-36 [23, 24]. Consisting of physician-rated pain, ROM, stability, and a patientrated daily function, MEPS [25] was the most widely used elbow function assessment, according to a systematic review including 980 studies and exploring trends and distributions of clinical rating systems in elbow 
research [26]. Construct validity was assessed by correlating LES to DASH, OES, MEPS, and SF-36 (PCS and MCS) in total scores (TOTAL), PAQ, CAS, EMC and ERS. Spearman's correlation coefficients (SCCs) were calculated. In this study, the Disability portion of DASH, the Elbow Function portion of OES, and the range of motion and daily activity function portion of MEPS comprised the EMC. The symptom portion of DASH, the pain portion of OES, and the pain and stability portions of MEPS comprised the ERS. The TOTAL, PAQ, and CAS portions of the LES were correlated with the TOTAL portions of DASH, OES, MEPS, and SF-36 (PCS and MCS). EMC and ERS portions of the LES were correlated with EMC and the ERS portions of DASH, OES and MEPS, as well as the TOTAL part of SF-36 (PCS and MCS).

\section{Responsiveness}

Responsiveness measures the sensitivity in changes in preoperative and follow-up results. In our study, the effect size (ES) and standardized response mean (SRM) were calculated for the TOTAL part of LES, DASH, OES, MEPS, and SF-36 (PCS and MCS) and the EMC and ERS parts of LES, DASH, OES, MEPS, as well as CAS and PAQ parts of LES. The ES was calculated as the mean difference between the baseline scores and the follow-up scores divided by the standard deviation of the baseline scores [27]. The SRM was calculated as the mean change in the scores divided by the standard deviation of the change in scores [28].

\section{Statistical analyses}

All statistical analyses were performed using IBM SPSS, Version 22.0 (IBM Corp, Armonk, NY, USA). Categorical data are presented as numbers (percentages). Continuous data are presented as means \pm standard deviations (range). $P$ values of less than 0.05 were considered statistically significant. Floor or ceiling effects existed when more than $15 \%$ of the patient collective achieved the highest or lowest possible score on the LES [29].SCC was considered strong for construct validity if the value was greater than 0.5 , moderate if the value was between 0.5 and 0.35 , and weak if the value was less than 0.35 [30]. An ES of 0.2 to 0.5 reflected small responsiveness, 0.5 to 0.8 , moderate responsiveness, and greater than 0.8 , large responsiveness, as well as SRM [31].

\section{Results}

All patients completed the PAQ with no difficulties and with no items missing or showing multiple responses. No floor or ceiling effects were found in the target population (Table 3). All of the SCCs were positive except the relationship with DASH, which was scored in a different direction (Table 4). The LES overall scores
Table 3 Floor and ceiling effects of LES

\begin{tabular}{|c|c|c|c|c|}
\hline \multirow[t]{2}{*}{ Component } & \multicolumn{2}{|l|}{ LES (No. $\left.{ }^{a}\right)$} & \multirow{2}{*}{$\begin{array}{l}\text { Floor } \\
\text { effect } \\
\left(\%^{b}\right)\end{array}$} & \multirow{2}{*}{$\begin{array}{l}\text { Ceiling } \\
\text { effect } \\
\left(\%^{b}\right)\end{array}$} \\
\hline & Lower limit & Upper limit & & \\
\hline TOTAL & $2.3(1)$ & $9.1(1)$ & 0 & 0 \\
\hline PAQ & $0.8(1)$ & $6.0(1)$ & 0 & 0 \\
\hline CAS & $1.1(1)$ & $3.1(2)$ & 0 & 1.6 \\
\hline EMC & $0.8(1)$ & $7.1(1)$ & 0 & 0 \\
\hline ERS & $1.1(1)$ & $2.0(4)$ & 0 & 6.4 \\
\hline
\end{tabular}

LES Liverpool Elbow Score, TOTAL total scores, PAQ patient-answered questionnaire part, CAS clinical assessment score part, EMC elbow motion capacity, ERS elbow-related symptoms

${ }^{a}$ Number of patients showing the lowest or highest values in various parts;

${ }^{b}$ Percent of patients achieving the lowest or highest values in various parts

correlated well with all the compared total scores $(p<$ 0.001 for all), as DASH $(r=0.89$ preoperatively and 0.86 post-operatively), OES ( $r=0.83$ and 0.79), MEPS $(r=0.66$ and 0.49), SF-36 (PCS, $r=0.65$ and 0.64; MCS, $r=0.45$ and 0.68 ), as well as with the PAQ and CAS parts of LES. The EMC and ERS parts of LES correlated either strongly or moderately with similar parts of DASH, OES, and MEPS as well as with SF-36/PCS and SF-36/MCS preoperatively and postoperatively. All in all, the different LES parts also correlated well with DASH, OES, MEPS, and SF-36, with either high or moderate correlations in TOTAL $(0.45-0.89)$, PAQ $(0.42-0.88)$, CAS $(0.35-$ $0.60)$, EMC (0.46-0.86), and ERS (0.36-0.59).

The LES was found to be more responsive (change from preoperative to follow up) than all the compared scores: DASH, OES, MEPS and SF-36 scores (Table 5).

Table 4 Construct validity. Spearman Correlation Coefficients (SCCS) between LES and DASH, OES, MEPS and SF-36

\begin{tabular}{llllll}
\hline & TOTAL & PAQ & CAS & EMC & ERS \\
\hline Preoperative data & & & & & \\
DASH & $0.89^{* * *}$ & $0.88^{* * *}$ & $0.44^{* * *}$ & $0.86^{* * *}$ & $0.54^{* * *}$ \\
OES & $0.83^{* * *}$ & $0.82^{* * *}$ & $0.45^{* * *}$ & $0.82^{* * *}$ & $0.51^{* * *}$ \\
MEPS & $0.66^{* * *}$ & $0.65^{* * *}$ & $0.38^{* *}$ & $0.67^{* * *}$ & $0.36^{* *}$ \\
SF-36/PCS & $0.65^{* * *}$ & $0.63^{* * *}$ & $0.42^{* *}$ & $0.60^{* * *}$ & $0.45^{* * *}$ \\
SF-36/MCS & $0.45^{* * *}$ & $0.42^{* *}$ & $0.35^{* *}$ & $0.50^{* * *}$ & $0.41^{* * *}$ \\
Follow-up data & & & & & \\
DASH & $0.86^{* * *}$ & $0.87^{* * *}$ & $0.57^{* * *}$ & $0.72^{* * *}$ & $0.59^{* * *}$ \\
OES & $0.79^{* * *}$ & $0.87^{* * *}$ & $0.46^{* * *}$ & $0.69^{* * *}$ & $0.54^{* * *}$ \\
MEPS & $0.49^{* * *}$ & $0.53^{* * *}$ & $0.35^{* *}$ & $0.46^{* * *}$ & $0.43^{* * *}$ \\
SF-36/PCS & $0.64^{* * *}$ & $0.50^{* * *}$ & $0.52^{* * *}$ & $0.52^{* * *}$ & $0.50^{* * *}$ \\
SF-36/MCS & $0.68^{* * *}$ & $0.50^{* * *}$ & $0.60^{* * *}$ & $0.60^{* * *}$ & $0.50^{* * *}$ \\
\hline
\end{tabular}

LES Liverpool Elbow Score, TOTAL total scores, PAQ patient-answered questionnaire, CAS clinical assessment score, EMC elbow motion capacity, ERS elbow-related symptoms, DASH Disability of arm, shoulder and hand questionnaire, OES Oxford Elbow Score, MEPS Mayo Elbow Performance Score, SF-36/PCS physical component summary part of Short Form-36, SF-36/MCS mental component summary part of Short Form-36, SCCS Spearman Correlation Coefficients

${ }^{*} P<0.01$, ${ }^{* * *} P<0.001$ 
Table 5 Responsiveness of LES compared with DASH, OES, MEPS and SF-36

\begin{tabular}{|c|c|c|c|c|c|c|}
\hline \multirow[t]{2}{*}{ Questionnaires } & \multicolumn{3}{|l|}{ Mean (SD) } & \multirow[t]{2}{*}{$P$ value } & \multirow[t]{2}{*}{ ES } & \multirow[t]{2}{*}{ SRM } \\
\hline & Preoperative & Follow-up & Change & & & \\
\hline \multicolumn{7}{|l|}{ LES } \\
\hline TOTAL & $5.7(1.3)$ & $8.8(0.8)$ & $3.1(1.4)$ & $<0.001$ & $2.80(\mathrm{~L})$ & $2.24(\mathrm{~L})$ \\
\hline PAQ & $3.4(1.1)$ & $5.5(0.5)$ & $2.1(1.2)$ & $<0.001$ & $2.34(\mathrm{~L})$ & $1.78(\mathrm{~L})$ \\
\hline CAS & $2.3(0.4)$ & $3.3(0.3)$ & $1.0(0.4)$ & $<0.001$ & $2.90(\mathrm{~L})$ & $2.34(\mathrm{~L})$ \\
\hline EMC & $3.9(1.2)$ & $6.9(0.7)$ & $3.0(1.3)$ & $<0.001$ & $2.92(L)$ & $2.35(\mathrm{~L})$ \\
\hline ERS & $1.8(0.2)$ & $1.9(0.2)$ & $0.1(0.2)$ & 0.001 & $0.55(\mathrm{M})$ & $0.52(\mathrm{M})$ \\
\hline \multicolumn{7}{|l|}{ DASH } \\
\hline TOTAL & $35(18)$ & $8(9)$ & $27(18)$ & $<0.001$ & $1.96(L)$ & $1.51(\mathrm{~L})$ \\
\hline EMC & $27(15)$ & $5(8)$ & $22(15)$ & $<0.001$ & $1.90(L)$ & $1.48(\mathrm{~L})$ \\
\hline ERS & $7(4)$ & $3(2)$ & $4(4)$ & $<0.001$ & $1.41(L)$ & $1.04(\mathrm{~L})$ \\
\hline \multicolumn{7}{|l|}{ OES } \\
\hline TOTAL & $61(16)$ & $88(9)$ & $27(17)$ & $<0.001$ & $2.12(L)$ & $1.65(\mathrm{~L})$ \\
\hline EMC & $65(19)$ & $95(11)$ & $30(19)$ & $<0.001$ & $1.99(\mathrm{~L})$ & $1.61(\mathrm{~L})$ \\
\hline ERS & $74(19)$ & $86(11)$ & $13(20)$ & $<0.001$ & $0.81(L)$ & $0.63(\mathrm{M})$ \\
\hline \multicolumn{7}{|l|}{ MEPS } \\
\hline TOTAL & $65(12)$ & $88(7)$ & $23(14)$ & $<0.001$ & $2.32(L)$ & $1.72(\mathrm{~L})$ \\
\hline EMC & $23(10)$ & $44(2)$ & $22(10)$ & $<0.001$ & $2.87(L)$ & $2.11(\mathrm{~L})$ \\
\hline ERS & $42(8)$ & $44(6)$ & $2(8)$ & 0.064 & $0.26(S)$ & $0.21(\mathrm{~S})$ \\
\hline \multicolumn{7}{|l|}{ SF-36 } \\
\hline PCS & $60(17)$ & $82(17)$ & $22(26)$ & $<0.001$ & $1.28(L)$ & $0.83(\mathrm{~L})$ \\
\hline MCS & $53(20)$ & $78(18)$ & $24(25)$ & $<0.001$ & $1.28(L)$ & $0.98(\mathrm{~L})$ \\
\hline
\end{tabular}

LES Liverpool Elbow Score, TOTAL total scores, PAQ patient-answered questionnaire, CAS clinical assessment score, EMC elbow motion capacity, ERS elbow-related symptoms, DASH Disability of arm, shoulder and hand questionnaire, OES Oxford Elbow Score, MEPS Mayo Elbow Performance Score, PCS physical component summary part, MCS mental component summary part, SD standard deviation, ES effect size, SRM standardized response mean

(L) a large responsiveness, ES of greater than 0.8 ; (M) a moderate responsiveness, ES of 0.5 to 0.8 ; and (S) a small responsiveness, ES of less than 0.5 ; as well as SRM

LES showed a large $(E S / S R M>0.8 / 0.8)$ responsiveness for TOTAL $(2.80 / 2.24, p<.001)$, and all parts of the PAQ, CAS, and EMC (except for ERS with a moderate responsiveness of $0.55 / 0.52, p=.001)$. This analysis also showed that LES was more responsive than DASH with an ES/SRM of 1.96/1.51 $(p<.001)$, OES of 2.12/ $1.65(p<.001)$, MEPS of $2.32 / 1.72(p<.001)$ and SF-36 (PCS, 1.28/0.83, $p<.001$ and MCS, 1.28/0.98, $p<.001$ ).

\section{Discussion}

The most important finding of this study was that the LES was a valid elbow-specific scoring system to evaluate joint functions in patients with elbow stiffness, and contains both subjective and objective parameters. It is based on a 15-item tool with a scale ranging from 0 to 10 points, with higher scores indicating better function.

The LES was simple enough to be rapidly administered in clinics and there were no ceiling or floor effects in our study, which demonstrated that the distribution of LES was satisfactory. Regrettably, reliability could not be measured due to the retrospective study design. Construct validity and responsiveness were assessed for validation. Because no gold standard measurement had been established for comparison of the construct validity between elbow scores, correlations (SCCs) of LES with previously validated scoring systems were determined by $0.44-0.89$ for DASH and $0.35-0.67$ for MEPS. In fact, validity was shown by good correlations with DASH $(r=0.79 ; r=0.89$ preoperatively and 0.86 postoperatively in our study) and NHP (Nottingham Health Profile, $r=0.54$ ) in the original publication study for arthritis [6]. Additionally, a good correlation (SCC, $0.84 ; 0.66$ in this study) was also shown with MEPS for patients undergoing total elbow arthroplasty [8]. Currently, the method of choice to determine responsiveness remains unknown, though various statistics are available [32]. The determination of the effective size (ES) and standardized response mean (SRM) in addition to the Global Perceived Effect (GPE) Score was considered to be an appropriate improvement to assess responsiveness [33]. Due to the retrospective nature of the study, ES and SRM were calculated and a large responsiveness was found in LES, which were larger than DASH, OES, MEPS, and SF-36 in our study. The responsiveness of LES was found to 
correlate well with DASH ( $r=0.45 ; 0.85$ in our study) and $\mathrm{NHP}(r=0.42)$ in the original study [6]. LES was also found to have large ES $(1.64 ; 2.80$ in our study), SRM (1.25; 2.24 in our study) and GRR (Guyatt responsiveness ratio, 1.69) during the follow-up period for patients undergoing elbow arthroplasty [32]. Interestingly, we found a lower responsiveness in ERS compared to DASH and OES. Our explanation for this difference was that there were extra stiffness items and quality of life items in the ERS of DASH, and the ERS of OES contains only items for pain, which would contribute to the bias of the comparison.

Recently, self-assessment scores in outcome studies are becoming more and more popular due to their financial and logistic advantages [34]. However, leaving objective parameters out might miss important aspects of elbow pathology that are important in symptom assessment and are impossible to evaluate by only using a self-assessment score. These aspects include elbow instability, reduced muscle strength, and nerve dysfunction. In fact, functions and symptoms in an individual joint may not be evaluated accurately by subjective questionnaires alone [35]. The questions presented to patients are also sometimes lengthy and not relevant to specific problems [36]. Objective parameters alone have been also found to have no correlation with patient's satisfaction [37], life background, since expectations and satisfaction are different for different individuals. Therefore, it is preferable for the LES to be used to evaluate the joint functions of patients with elbow stiffness by using self-assessment questionnaires in addition to physician-assessment parameters.

However, there are also some weaknesses that need to be realized when using the LES to evaluate joint function in patients with elbow stiffness. The researchers that invented the LES decided to remove the instability test from the objective parameters as they thought it was associated with a rare elbow problem. When presented, it would have such a massive impact on elbow function that it would be easily detected [6]. However, according to our clinical experience, we believe that elbow instability is a perfect sign of collateral ligament dysfunction, which is a common complication in elbow trauma, and an indication for surgical therapeutic options and postoperative rehabilitation. Therefore, it would be better if instability was considered. For measuring strength as an elbow specific function, the MRC scale was used in most systems, as was the LES, which is a subjective qualitative assessment made by the surgeons. However, $\mathrm{L}$ Shahgholi. found that half of the patients clinically assessed as having normal (5/5) elbow flexion strength on manual muscle testing exhibited less than $42 \%$ of their age-expected strength on quantitative testing, as well as elbow extension strength testing. They concluded that even when performed by experienced clinicians, manual muscle testing may be more misleading than expected for subjects graded as having normal (5/5) strength [38, 39].
Therefore, measuring strength with a dynamometer would be a more objective and responsive measure than measuring strength with the MRC scale, and it could be measured over time and compared to normative data. Strength associated with grip, elbow and wrist motion are all necessary in assessing elbow function, especially in patients planning for elbow arthrolysis surgery, as reduced muscle strength is a common complication after arthrolysis [40]. Additionally, pain has a strong impact on elbow function and health status measures [41]. Due to the strong influence of psychological and sociological factors on the experience of pain, the expression of pain should probably be evaluated separately from objective parameters in physician-rated domains [42]. Though the expression of pain is obtained from the PAQ portion of the LES, it comprises only $1 / 9(\sim$ $11 \%)$ of the PAQ and $1 / 15(\sim 7 \%)$ of the whole scores, which is in contrast to most of other scoring systems, in which pain is weighted as $30-50 \%$ of the total score [4, 5]. In fact, a five-level Likert scale could not fully generalize the expression of pain from patients and detect its changes from pre- to post-operation. We believe that these limitations may also contribute to its moderate responsiveness in the ERS. Finally, according to the International Classification of Functioning, Disability and Health (ICF), health and disability would be better measured in three domains: physician-rated body functions and structures, patient-rated activities and participation, and patient-rated quality of life [43]. Unfortunately, LES does not include items inquiring about patients' qualities of life.

This study has some weaknesses. The biggest limitation of this study was that the test-retest reliability and internal consistency could not be validated due to the retrospective nature of the study, which is an important step (i.e. reliability) in evaluating a scoring system. The retrospective study could contribute to the bias in the validated results. Another limitation is that as it was a single-centre study, and it could not be said with certainty that these results could be applied to other centres. Therefore, further prospective research with a larger population from multiple clinical centres is needed.

\section{Conclusion}

Based on the present data, our results suggested that the LES is a valid elbow-specific scoring system and is applicable to evaluate joint functions of patients with elbow stiffness, although some items included had some weakness either. Further prospective research using a larger population from multiple clinical centres is required in future. 


\section{Abbreviations}

CAS: Clinical assessment score; DASH: Disability of arm, shoulder and hand questionnaire; EMC: Elbow motion capacity; ERS: Elbow-related symptoms; ES: Effect size; LES: Liverpool Elbow Score; MEPS: Mayo Elbow Performance Score; OES: Oxford Elbow Score; PAQ: Patient-answered questionnaire; SCC: Spearman correlation coefficients; SF-36: Short Form-36; SF-36/ MCS: Mental component summary part of Short Form-36; SF-36/ PCS: Physical component summary part of Short Form-36; SRM: Standardized response mean

\section{Acknowledgements}

This study was supported by the Department of Orthopaedics from Shanghai Sixth People's Hospital East Affiliated to Shanghai University of Medicine \& Health Sciences. The authors would like to thank the personnel from the elbow stiffness clinical team leading by prof. FCY for participating in the patient and data collection.

\section{Availability of data and materials}

The data and materials contributing to this article may be made available upon request by sending an e-mail to the first author.

\section{Authors' contributions}

SZY conceived and designed this study, performed the literature searches, extracted the data, performed the statistical analyses, interpreted the data and drafted the manuscript. FCY revised the manuscript and acted as guarantor for the paper. The guarantors accept full responsibility for the conduct of the study, had access to the data, and controlled the decision to publish. Both authors approved the final manuscript.

\section{Ethics approval and consent to participate}

The Ethics Committee of Shanghai Jiao Tong University Affiliated Sixth People's Hospital concluded that no approval is necessary for study based on its retrospective design. Data were analyzed anonymously; all patients approved the results of this study by oral consent. The oral consent approval was documented in the patients' files. This was approved by the Ethics Committee of Shanghai Jiao Tong University Affiliated Sixth People's Hospital. All clinical investigations were conducted in accordance with the guidelines of the Declaration of Helsinki.

\section{Consent for publication}

Not applicable.

\section{Competing interests}

The authors declare that they have no competing interests.

\section{Publisher's Note}

Springer Nature remains neutral with regard to jurisdictional claims in published maps and institutional affiliations.

\section{Received: 27 February 2018 Accepted: 7 August 2018}

Published online: 21 August 2018

\section{References}

1. Ranganathan K, Loder S, Agarwal S, Wong WW, Forsberg J, Davis TA, Wang S, James AW, Levi B. Heterotopic ossification: basic-science principles and clinical correlates. J Bone Joint Surg Am. 2015;97(13):1101-11.

2. Hildebrand KA, Zhang M, Befus AD, Salo PT, Hart DA. A myofibroblast-mast cell-neuropeptide axis of fibrosis in post-traumatic joint contractures: an in vitro analysis of mechanistic components. J Orthop Res. 2014;32(10):1290-6.

3. Doornberg JN, Bosse T, Cohen MS, Jupiter JB, Ring D, Kloen P. Temporary presence of myofibroblasts in human elbow capsule after trauma. J Bone Joint Surg Am. 2014;96(5):e36.

4. Longo UG, Franceschi F, Loppini M, Maffulli N, Denaro V. Rating systems for evaluation of the elbow. Br Med Bull. 2008;87:131-61.

5. Smith MV, Calfee RP, Baumgarten KM, Brophy RH, Wright RW. Upper extremity-specific measures of disability and outcomes in orthopaedic surgery. J Bone Joint Surg Am. 2012;94(3):277-85.

6. Sathyamoorthy P, Kemp GJ, Rawal A, Rayner V, Frostick SP. Development and validation of an elbow score. Rheumatology (Oxford, England). 2004; 43(11):1434-40.
7. Dawson J, Doll H, Boller I, Fitzpatrick R, Little C, Rees J, Carr A. Comparative responsiveness and minimal change for the Oxford elbow score following surgery. Qual Life Res Int J Qual Life Asp Treat Care Rehab. 2008;17(10): 1257-67.

8. Ashmore AM, Gozzard C, Blewitt N. Use of the Liverpool elbow score as a postal questionnaire for the assessment of outcome after total elbow arthroplasty. J Shoulder Elb Surg. 2007;16(3 Suppl):S55-8.

9. Amirfeyz R, Blewitt N. Mid-term outcome of GSB-III total elbow arthroplasty in patients with rheumatoid arthritis and patients with post-traumatic arthritis. Arch Orthop Trauma Surg. 2009;129(11):1505-10.

10. Munoz-Mahamud E, Fernandez-Valencia JA, Riba J. Plate osteosynthesis for severe olecranon fractures. J Orthop Surg (Hong Kong). 2010;18(1):80-4.

11. Reising K, Hauschild O, Strohm PC, Suedkamp NP. Stabilisation of articular fractures of the distal humerus: early experience with a novel perpendicular plate system. Injury. 2009:40(6):611-7.

12. Kalogrianitis S, Sinopidis C, El Meligy M, Rawal A, Frostick SP. Unlinked elbow arthroplasty as primary treatment for fractures of the distal humerus. J Shoulder Elb Surg. 2008;17(2):287-92.

13. Beirer $M$, Friese $H$, Lenich $A$, Cronlein M, Sandmann GH, Biberthaler $P$, Kirchhoff $C$ Siebenlist S. The elbow self-assessment score (ESAS): development and validation of a new patient-reported outcome measurement tool for elbow disorders. Knee Surg, Sports Traumatol, Arthrosc. 2017;25(7):2230-6.

14. Chen $\mathrm{H}$, Ji X, Zhang W, Zhang $Y$, Zhang L, Tang P. Validation of the simplified Chinese (mainland) version of the disability of the arm, shoulder, and hand questionnaire (DASH-CHNPLAGH). J Orthop Surg Res. 2015;10:76.

15. Li L, Wang HM, Shen Y. Chinese SF-36 health survey: translation, cultural adaptation, validation, and normalisation. J Epidemiol Community Health. 2003:57(4):259-63

16. Guillemin F. Cross-cultural adaptation and validation of health status measures. Scand J Rheumatol. 1995;24(2):61-3.

17. Guillemin F, Bombardier C, Beaton D. Cross-cultural adaptation of healthrelated quality of life measures: literature review and proposed guidelines. J Clin Epidemiol. 1993;46(12):1417-32.

18. Yu S, Chen M, Fan C. Team Approach: Elbow Contracture Due to Heterotopic Ossification. JBJS reviews. 2017;5(1) https://doi.org/10.2106/JBJS.RWW.16.00008.

19. Barrett $P$, Kline P. The Observation to Variable Ratio in Factor Analysis, vol. 1; 1981

20. Terwee CB, Bot SD, de Boer MR, van der Windt DA, Knol DL, Dekker J, Bouter $\mathrm{LM}$, de Vet HC. Quality criteria were proposed for measurement properties of health status questionnaires. J Clin Epidemiol. 2007;60(1):34-42.

21. The $B$, Reininga $I H$, El Moumni M, Eygendaal D. Elbow-specific clinical rating systems: extent of established validity, reliability, and responsiveness. J Shoulder Elb Surg. 2013;22(10):1380-94.

22. Beaton DE, Katz JN, Fossel AH, Wright JG, Tarasuk V, Bombardier C. Measuring the whole or the parts? Validity, reliability, and responsiveness of the disabilities of the arm, shoulder and hand outcome measure in different regions of the upper extremity. J Hand Ther. 2001;14(2):128-46.

23. Dawson J, Doll H, Boller I, Fitzpatrick R, Little C, Rees J, Jenkinson C, Carr AJ. The development and validation of a patient-reported questionnaire to assess outcomes of elbow surgery. J Bone Joint Surg Br Vol. 2008;90(4):466-73.

24. SooHoo NF, McDonald AP, Seiler JG 3rd, McGillivary GR. Evaluation of the construct validity of the DASH questionnaire by correlation to the SF-36. J Hand Surg. 2002;27(3):537-41.

25. Morrey BF, Adams RA. Semiconstrained arthroplasty for the treatment of rheumatoid arthritis of the elbow. J Bone Joint Surg Am. 1992;74(4): 479-90.

26. Evans JP, Smith CD, Fine NF, Porter I, Gangannagaripalli J, Goodwin VA, Valderas JM. Clinical rating systems in elbow research-a systematic review exploring trends and distributions of use. J Shoulder Elbow Surg. 2018;27: e98-e106.

27. Kazis LE, Anderson JJ, Meenan RF. Effect sizes for interpreting changes in health status. Med Care. 1989;27(3 Suppl):S178-89.

28. Peolsson A, Vavruch L, Hedlund R. Long-term randomised comparison between a carbon fibre cage and the Cloward procedure in the cervical spine. Eur Spine J. 2007:16(2):173-8

29. McHorney CA, Tarlov AR. Individual-patient monitoring in clinical practice: are available health status surveys adequate? Qual Life Res Int J Qual Life Asp Treat Care Rehab. 1995:4(4):293-307.

30. Kim SJ, Basur MS, Park CK, Chong S, Kang YG, Kim MJ, Jeong JS, Kim TK. Crosscultural adaptation and validation of the Korean version of the new knee society knee scoring system. Clin Orthop Relat Res. 2017 475(6):1629-39. 
31. Revicki D, Hays RD, Cella D, Sloan J. Recommended methods for determining responsiveness and minimally important differences for patient-reported outcomes. J Clin Epidemiol. 2008;61(2):102-9.

32. Vishwanathan $\mathrm{K}$, Alizadehkhaiyat $\mathrm{O}$, Kemp GJ, Frostick SP. Responsiveness of the Liverpool elbow score in elbow arthroplasty. J Shoulder Elb Surg. 2013; 22(3):312-7.

33. de Vet $\mathrm{HC}$, Terwee $\mathrm{CB}$, Ostelo RW, Beckerman H, Knol DL, Bouter LM. Minimal changes in health status questionnaires: distinction between minimally detectable change and minimally important change. Health Qual Life Outcomes. 2006;:54

34. Siemiatycki J. A comparison of mail, telephone, and home interview strategies for household health surveys. Am J Public Health. 1979;69(3):238-45.

35. Beaton DE, Richards RR. Measuring function of the shoulder. A cross-sectiona comparison of five questionnaires. J Bone Joint Surg Am. 1996;78(6):882-90.

36. Patrick DL, Deyo RA. Generic and disease-specific measures in assessing health status and quality of life. Med Care. 1989;27(3 Suppl):S217-32.

37. Capuano L, Poulain S, Hardy P, Longo UG, Denaro V, Maffulli N. No correlation between physicians administered elbow rating systems and patient's satisfaction. J Sports Med Phys Fitness. 2011;51(2):255-9.

38. Shahgholi L, Bengtson KA, Bishop AT, Shin AY, Spinner RJ, Basford JR, Kaufman KR. A comparison of manual and quantitative elbow strength testing. Am J Phys Med Rehab. 2012;91(10):856-62.

39. Werle S, Goldhahn J, Drerup S, Simmen BR, Sprott H, Herren DB. Age- and gender-specific normative data of grip and pinch strength in a healthy adult Swiss population. J Hand Surg Eur Vol. 2009;34(1):76-84.

40. Cai J, Wang W, Yan H, Sun Y, Chen W, Chen S, Fan C. Complications of open elbow Arthrolysis in post-traumatic elbow stiffness: a systematic review. PLoS One. 2015;10(9):e0138547.

41. Elliott TE, Renier CM, Palcher JA. Chronic pain, depression, and quality of life: correlations and predictive value of the SF-36. Pain Med (Malden, Mass). 2003;4(4):331-9.

42. Doornberg JN, Ring D, Fabian LM, Malhotra L, Zurakowski D, Jupiter JB. Pain dominates measurements of elbow function and health status. J Bone Joint Surg Am. 2005;87(8):1725-31.

43. Organization WH. International classification of functioning, Disability and Health (ICF). In: Kirch W, ed. Encyclopedia of Public Health. Dordrecht: Springer Netherlands. 2008:217-20.

Ready to submit your research? Choose BMC and benefit from:

- fast, convenient online submission

- thorough peer review by experienced researchers in your field

- rapid publication on acceptance

- support for research data, including large and complex data types

- gold Open Access which fosters wider collaboration and increased citations

- maximum visibility for your research: over $100 \mathrm{M}$ website views per year

At $\mathrm{BMC}$, research is always in progress.

Learn more biomedcentral.com/submissions 